\title{
Business Process Management System Modeling in the Virtual Enterprise based on Stochastic Colored Petri Net
}

\author{
De-Long Zhang, Xiao-Zhong $\mathrm{Li}^{\mathrm{a}}$, Xiao-Peng Li \\ College of Computer Science and Information Engineering In Tianjin University of Science \& \\ Technology, China \\ alixz@tust.edu.cn
}

Keywords: Virtual enterprise; BPM; SCPN;

\begin{abstract}
Traditional enterprise information systems have many defects, so business process management (BPM) system was applied to the virtual enterprise and virtual enterprise process model is established based on BPM system. The dominant enterprise and the member enterprises used BPM system for their own information management system in the virtual enterprise. The BPM system model of the virtual enterprise was divided into the formation process and the operation process. The analysis method based on stochastic colored Petri net(SCPN) was also presented which can be used to model and analyze the process model in order to obtain the system performance analysis data. The virtual enterprise resources utilization rate can be seen. The model extends the application area of BPM system and provides a reference for the construction and management of virtual enterprise.
\end{abstract}

\section{Introduction}

With the global economic integration and the rapid development of information technology in recent years, the virtual enterprise has become an important business model. It is a corporation organization which achieves complementary advantages as well as quickly grasps the market opportunities by sharing risks and resources among a number of companies. A virtual enterprise is virtual in its location and technology ${ }^{[1]}$. It only retains its key department while virtualizing or omitting other departments.

Information system is the basis of virtual enterprise to achieve efficient operations ${ }^{[2]}$, but there are some problems such as isolated islands of information in the traditional information systems ${ }^{[3]}$. With the development of information technology, BPM technology has gradually grown up. BPM provides enterprises with the ability of management process, and its life cycle includes process modeling, implementation, management and optimization ${ }^{[4]}$. The four parts of its life cycle can achieve the continuous improvement of the process. Reference [5] mentioned several major direction of BPM in the future, one of which is some applications of BPM in virtual enterprises. But currently there is less research on BPM in virtual enterprises. Therefore the paper proposes a framework of BPM technology-based virtual enterprise information system and establishes the process model of this framework.

Enterprise modeling is abstract activities of the enterprise for the description of certain aspects of the enterprise. Process modeling is an accurate description of the business process and important foundation of enterprise process analysis, optimization and control. Because the virtual enterprise information system has many features such as members heterogeneous and structure change complex, it's difficult for the traditional Unified Modeling Language, entity-relationship model and other Modeling language to meet the needs of virtual enterprise information system modeling ${ }^{[6]}$. Petri net is a kind of modeling language. It takes the visible graphic description, and is supported by formalized mathematical method. Petri net can express the static structure and the dynamic change in the discrete event dynamic system that is used to analyze static and dynamic problems of the business process $^{[7]}$. Reference [8] with Petri net successfully completed the design of the virtual enterprise workflow system. But there are many problems such as too large scale of the model and lack of mathematical methods to analyze system performance in Petri net model. In order to overcome these shortcomings, people study many different high-level Petri nets. Colored Petri net reduces the scale 
of the system by introducing color token, and stochastic Petri net provides an effective mathematical theory tool for model performance evaluation by introducing time factor to transitions. The paper uses a kind of SCPN to model and analyze the virtual enterprise BPM system.

\section{Stochastic colored Petri net}

SCPN can be defined as a seven-tuple:

$\mathrm{SCPN}=\left\{P, T, A, C, E, M_{0}, \lambda\right\}$ where

$P$ is a finite set of places;

$T$ is a finite set of transitions;

$A$ is a set of arcs;

$C$ is the color-function defined from $\mathrm{P}$ and $\mathrm{T}$ into non-empty sets.

$E$ is the expression of arcs;

$M_{0}$ is the initial marking;

$\lambda$ is the firing rate of transitions.

The transition firing rules of SCPN and CPN are same ${ }^{[9]}$.

Each token residing in place has a color in SCPN, which tends to engender the space explosion problem in the SCPN of complex system ${ }^{[10]}$. In order to overcome this problem, the paper divides SCPN into several relatively independent sub-models ${ }^{[11]}$. It can reduce the size of the system and prevent the emergence of the space explosion problem by analysis of each sub-model.

\section{The operation architecture of virtual enterprise BPM system}

The operation architecture of virtual enterprise BPM system is shown in Fig. 1:

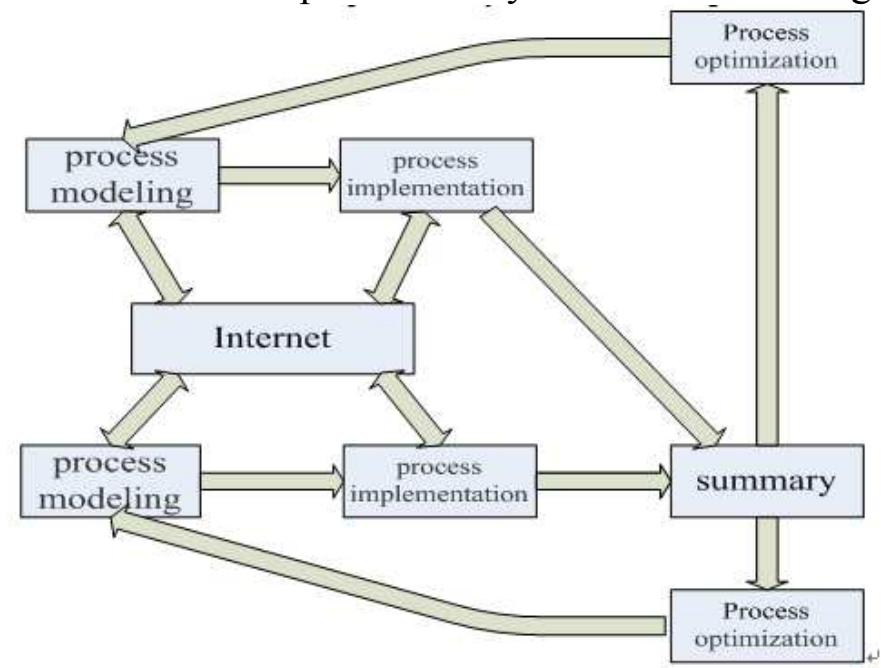

Figure 1. The operation architecture of virtual enterprise BPM system

In this architecture, every enterprise use BPM system for their own information management system, the member enterprises release their process information in the form of services to the network, the dominant enterprise finds their own services through the network to contract with service-provided enterprises, provides an overall process modeling through the service process from the member enterprises. The dominant enterprise notifies their members to implement process and provides to a final summary to complete the whole process, then the dominant enterprise and the member companies would analysis process data for process optimization or redesign and prepare for the next virtual enterprise running. Throughout the process, the BPM system is responsible for process design, packaging business functions for the service and managing processes operation, the collection of process execution data and process optimization. 


\section{BPM system model of virtual enterprise based on the stochastic colored Petri net}

The BPM system model of the virtual enterprise is divided into two parts: the first part is the formation process model of the virtual enterprise. The second part is the operation process model of virtual enterprise.

Modeling and analysis of the virtual enterprise formation process. The SCPN of virtual enterprise formation process based on CPN Tool software is shown in Fig. 2:

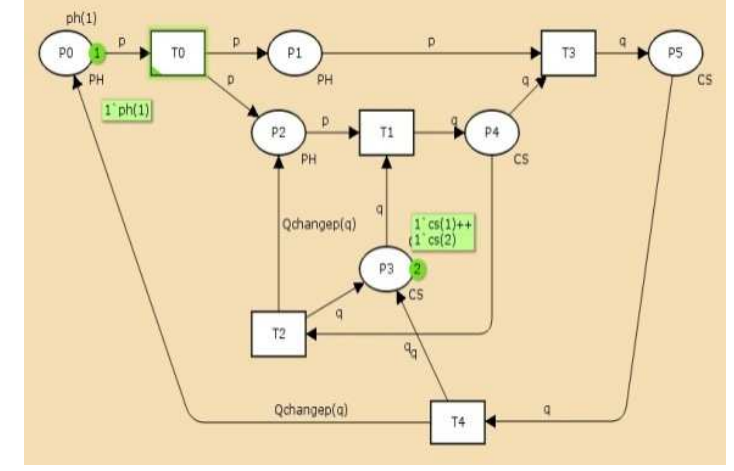

Figure 2. The SCPN of virtual enterprise formation process

The meaning of the various places and transitions are shown in Table. 1:

Table 1 The Meaning Of The Various Places And Transitions

\begin{tabular}{cccc}
\hline Place & Meaning & Transition & Meaning \\
\hline P0 & Grasps the market opportunities & T0 & Demand analysis \\
P1 & Wait for the signing of a cooperation & T1 & Select a cooperative enterprise \\
& agreement & T2 & Re-select \\
P2 & Ready to select the cooperative enterprise & T3 & Enter into a cooperation agreement \\
P3 & Selected cooperative enterprise information set & T4 & Wait for the next market opportunities \\
P4 & Assess selected cooperative enterprise & & \\
P5 & Complete & & \\
\hline
\end{tabular}

$\mathrm{PH}, \mathrm{CS}$ are respectively the message color set and selected information color set of cooperative enterprise, $\mathrm{ph}(1)$ is the message passed token in the running process, $\mathrm{P} 0$ is the dominant enterprise waiting for the market opportunities, when market opportunity occurs, the dominant enterprise grasps opportunity for business analysis to select the enterprise services repository, $\operatorname{cs}(1)$ and $\operatorname{cs}(2)$ are two color tokens, which show different services process from two enterprises. The dominant enterprise assesses the service process by P4, and if the assessment is approved, the dominant enterprise enters into cooperation agreements with enterprises that provide this service process. Set the change delay coefficient $\lambda=(2,5,7,3,10)$. The reachable markings are shown in Table. 2 :

CPN Tool simulation shows that each transition of the model is live, and each place is bounded. Each marking Mi steady-state probability is:

$P\left(M_{0}\right)=0.3947, P\left(M_{1}\right)=0.2631, P\left(M_{2}\right)=0.1316, P\left(M_{3}\right)=0.1316, P\left(M_{4}\right)=0.0395, P\left(M_{5}\right)=0.0395$.

The probability of $P_{0}, P_{1}, P_{2}, P_{3}$ and $P_{4}, P_{5}$ containing the token is shown by $P r$.

Table 2 The Reachable Markings

\begin{tabular}{ccccccc}
\hline & $P_{0}$ & $P_{1}$ & $P_{2}$ & $P_{3}$ & $P_{4}$ & $P_{5}$ \\
\hline$M_{0}$ & $1 ' p h(1)$ & 0 & 0 & $1^{\prime} \operatorname{cs}(1)+1 ' \operatorname{cs}(2)$ & 0 & 0 \\
$M_{1}$ & 0 & $1^{\prime} p h(1)$ & $1^{\prime} p h(1)$ & $1^{\prime} \operatorname{cs}(1)+1 ' \operatorname{cs}(2)$ & 0 & 0 \\
$M_{2}$ & 0 & $1^{\prime} p h(1)$ & 0 & $1 ' \operatorname{cs}(1)$ & $1^{\prime} \operatorname{cs}(2)$ & 0 \\
$M_{3}$ & 0 & $1^{\prime} p h(1)$ & 0 & $1^{\prime} \operatorname{cs}(2)$ & $1^{\prime} \operatorname{cs}(1)$ & 0 \\
$M_{4}$ & 0 & 0 & 0 & $1^{\prime} \operatorname{cs}(1)$ & 0 & $1^{\prime} \operatorname{cs}(2)$ \\
$M_{5}$ & 0 & 0 & 0 & $1^{\prime} \operatorname{cs}(2)$ & 0 & $1^{\prime} \operatorname{cs}(1)$ \\
\hline
\end{tabular}




\section{$\operatorname{Pr}\left(P_{0}=1^{\prime} p h(1)\right)=0.3947, \operatorname{Pr}\left(P_{1}=1^{\prime} p h(1)\right)=0.5263, \operatorname{Pr}\left(P_{2}=1^{\prime} p h(1)\right)=0.3947$, \\ $\operatorname{Pr}\left(P_{3}=1{ }^{\prime} \operatorname{cs}(1)+1{ }^{\prime} \operatorname{cs}(2)\right)=0.6578, \operatorname{Pr}\left(P_{3}=1^{\prime} \operatorname{cs}(1)\right)=\operatorname{Pr}\left(P_{3}=1 ' \operatorname{cs}(2)\right)=0.1711$ \\ $\operatorname{Pr}\left(P_{4}=1{ }^{\prime} \operatorname{cs}(1)\right)=\operatorname{Pr}\left(P_{4}=1^{\prime} \operatorname{cs}(2)\right)=0.1316, \operatorname{Pr}\left(P_{5}=1^{\prime} \operatorname{cs}(1)\right)=\operatorname{Pr}\left(P_{5}=1^{\prime} \operatorname{cs}(2)\right)=0.0395$}

$K_{1}$ stands for service processes information utilization of selected enterprise. By Fig. 2, $K_{1}=\left\{P_{3}=1^{\prime} \operatorname{cs}(1)+1^{\prime} \operatorname{cs}(2), P_{3}=1^{\prime} \operatorname{cs}(1), P_{3}=1^{\prime} \operatorname{cs}(2)\right\}$, available $P\left(K_{1}\right)=\operatorname{Pr}\left(P_{3}=1^{\prime} c s(1)+1^{\prime} c s(2)\right)+$ $\operatorname{Pr}\left(P_{3}=1^{\prime} \operatorname{cs}(1)\right)+\operatorname{Pr}\left(P_{3}=1^{\prime} \operatorname{cs}(2)\right)=1$. $P n$ is the sum of the steady-state probability and get of $P n=2.6579$, and ultimately get $P\left(K_{l}\right) / P n=0.3762$, it can be seen that the virtual enterprise information resources utilization rate is $37.62 \%$, As the query of the enterprise services process information is through the network, to improve the efficiency in the use of information resources will help accelerate the efficiency of the formation of virtual enterprises.

Modeling and analysis of the virtual enterprise operation process. After the formation process of the virtual enterprise is completed, the dominant enterprise and the member enterprises begin to complete the cooperative projects through the BPM system, the SCPN is shown in Fig. 3.

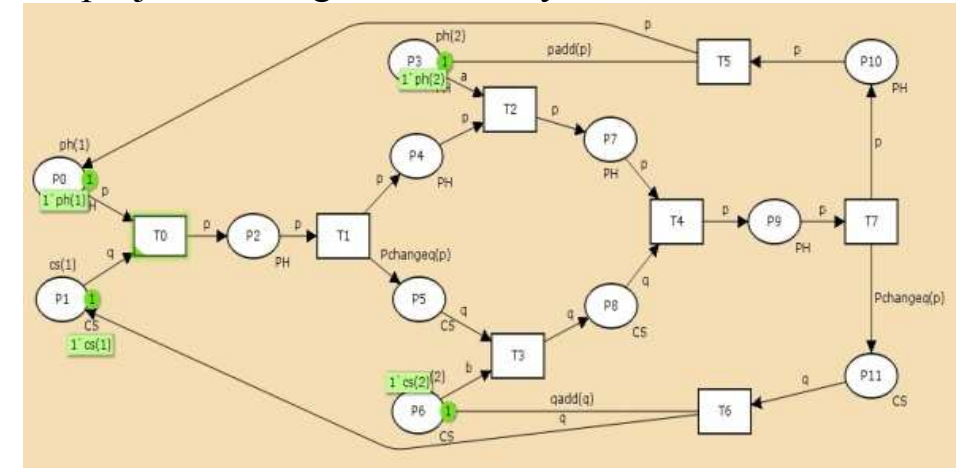

Figure 3. The SCPN of virtual enterprise operation process

The meaning of the various places and transitions are shown in Table 3:

Table 3 The Meaning Of The Various Places And Transitions

\begin{tabular}{cccc}
\hline Place & Meaning & Transition & Meaning \\
\hline P0 & Process information of the dominant enterprise & T0 & Process design \\
P1 & Process information of the member enterprises & $\mathrm{T} 1$ & Ready to run processes \\
P2 & Completion of the process design & $\mathrm{T} 2$ & The dominant enterprise run the process \\
P3 & A set of the dominant enterprise process resources & $\mathrm{T} 3$ & The member enterprise run the process \\
P4 & The dominant business process instantiation & $\mathrm{T} 4$ & Process summary \\
P5 & The member enterprises process instantiation & $\mathrm{T} 5$ & The dominant enterprises update the process \\
P6 & A set of process resources of member companies & $\mathrm{T} 6$ & The member enterprise update the process \\
P7 & The dominant business process execution completes & $\mathrm{T} 7$ & Analysis the process execution data \\
P8 & The member enterprises process execution completes & & \\
P9 & Completion of the process Summary & & \\
P10 & The dominant enterprise optimize the process & & \\
P11 & The member enterprise s optimize the process & &
\end{tabular}

PH stands for color set of the dominant enterprise information resources, CS stands for color set of information resources of the member enterprises, $p h(1)$ and $\operatorname{cs}(1)$ are the enterprises process messages, $p h(2)$ and $c s(2)$ are the enterprises process resources. After the dominant enterprise gets the service process information of members, it combines with its own process information and starts the overall process design. Then the dominant enterprise informs the member enterprises to run processes and the enterprises call themselves process resources for the process instance and run the process, the dominant enterprise summarizes all the process. When the overall process has finished running, the enterprises analysis the process execution data, optimize their process and update the process of resource allocation to get ready for the next process running. Set the change delay coefficient $\lambda=(3$, $6,1,1,2,7,7,4)$. The reachable markings are shown in Table 4: 
Table 4 The Reachable Markings

\begin{tabular}{|c|c|c|c|c|c|c|c|c|c|c|c|c|}
\hline & $P_{0}$ & $P_{1}$ & $P_{2}$ & $P_{3}$ & $P_{4}$ & $P_{5}$ & $P_{6}$ & $P_{7}$ & $P_{8}$ & $P_{9}$ & $P_{10}$ & $P_{I I}$ \\
\hline$M_{0}$ & 1'ph(1) & $1^{\prime} \operatorname{cs}(1)$ & 0 & 1'ph(2) & 0 & 0 & $1^{\prime} \operatorname{cs}(2)$ & 0 & 0 & 0 & 0 & 0 \\
\hline$M_{1}$ & 0 & 0 & 1'ph(1) & $1^{\prime} p h(2)$ & 0 & 0 & $1^{\prime} \operatorname{cs}(2)$ & 0 & 0 & 0 & 0 & 0 \\
\hline$M_{2}$ & 0 & 0 & 0 & 1'ph(2) & $1^{\prime} p h(1)$ & $1^{\prime} \operatorname{cs}(1)$ & $1^{\prime} \operatorname{cs}(2)$ & 0 & 0 & 0 & 0 & 0 \\
\hline$M_{3}$ & 0 & 0 & 0 & 0 & 0 & $1^{\prime} \operatorname{cs}(1)$ & $1^{\prime} \operatorname{cs}(2)$ & $1^{\prime} p h(1)$ & 0 & 0 & 0 & 0 \\
\hline$M_{4}$ & 0 & 0 & 0 & $1^{\prime} p h(2)$ & $1^{\prime} p h(1)$ & 0 & 0 & $1^{\prime} \operatorname{cs}(1)$ & 0 & 0 & 0 & 0 \\
\hline$M_{5}$ & 0 & 0 & 0 & 0 & 0 & 0 & 0 & $1^{\prime} p h(1)$ & $1^{\prime} \operatorname{cs}(1)$ & 0 & 0 & 0 \\
\hline$M_{6}$ & 0 & 0 & 0 & 0 & 0 & 0 & 0 & 0 & 0 & 1'ph(1) & 0 & 0 \\
\hline$M_{7}$ & 0 & 0 & 0 & 0 & 0 & 0 & 0 & 0 & 0 & 0 & 1'ph(1) & $1^{\prime} \operatorname{cs}(1)$ \\
\hline$M_{8}$ & $1^{\prime} p h(1)$ & 0 & 0 & $1^{\prime} p h(2)$ & 0 & 0 & 0 & 0 & 0 & 0 & 0 & $1^{\prime} \operatorname{cs}(1)$ \\
\hline$M_{9}$ & 0 & $1^{\prime} \operatorname{cs}(1)$ & 0 & 0 & 0 & 0 & $1^{\prime} \operatorname{cs}(2)$ & 0 & 0 & 0 & 1'ph(1) & 0 \\
\hline
\end{tabular}

Each marking Mi steady-state probability is:

$P\left(M_{0}\right)=0.1124, P\left(M_{1}\right)=0.0562, P\left(M_{2}\right)=0.1687, P\left(M_{3}\right)=0.1687, P\left(M_{4}\right)=0.1687, P\left(M_{5}\right)=0.1687$, $P\left(M_{6}\right)=0.0843, P\left(M_{7}\right)=0.0241, P\left(M_{8}\right)=0.0241, P\left(M_{9}\right)=0.0241$.

The probability of each place own token:

$\operatorname{Pr}\left(P_{0}=1\right.$ ' $\left.p h(1)\right)=0.1365, \operatorname{Pr}\left(P_{1}=1\right.$ ' $\left.c s(1)\right)=0.1365, \operatorname{Pr}\left(P_{2}=1\right.$ ' $\left.p h(1)\right)=0.0562, \operatorname{Pr}\left(P_{3}=1\right.$ 'ph $\left.(2)\right)=0.5301$

$\operatorname{Pr}\left(P_{4}=1 ' \operatorname{ph}(1)\right)=0.3374, \operatorname{Pr}\left(P_{5}=1\right.$ 'cs $\left.(1)\right)=0.3374, \operatorname{Pr}\left(P_{6}=1\right.$ 'cs $\left.(2)\right)=0.5301, \operatorname{Pr}\left(P_{7}=1\right.$ 'ph $\left.(1)\right)=0.3374$

$\operatorname{Pr}\left(P_{8}=1 ' c s(1)\right)=0.3374, \operatorname{Pr}\left(P_{9}=1 ' p h(1)\right)=0.0843$

$\operatorname{Pr}\left(P_{10}=1 ' p h(1)\right)=0.0482, \operatorname{Pr}\left(P_{11}=1^{\prime} \operatorname{cs}(1)\right)=0.0482$

$K_{2}$ is resource utilization for the selected business process. $K_{2}=\left\{P_{3}=1^{\prime} p h(2), P_{6}=1^{\prime} \operatorname{cs}(2)\right\}$, $P\left(K_{2}\right)=\operatorname{Pr}\left(P_{3}=1^{\prime} p h(2)\right)+\operatorname{Pr}\left(P_{6}=1^{\prime} c s(2)\right)=1.0602 . P m$ is the sum of the steady-state probability and get of $P m=2.6467$ and ultimately receive $P\left(K_{l}\right) / P m=0.4005$, the calculated results show that the utilization rate of resources is $40.05 \%$, it is not high. Because in BPM system, process design and optimization takes a lot of time, when the flow of resources is likely to idle. The effective use of idle process resources in process design and optimization phase will make it possible to raise the enterprise efficiency.

\section{Conclusions}

The paper introduced the BPM system into the virtual enterprise. By using the advantage of the BPM concept, enterprises can overcome the shortcomings of traditional information systems and seize market opportunities. Establishing a process model for the virtual enterprise BPM system based on SCPN can expand its role in the field of system modeling, reflect the running characteristics of the system and show the operation characteristics of cross organization process. It makes people understand the system's running process, the virtual enterprise's operation mechanism and provides some new ideas for research and development of virtual enterprise and the related theory of BPM.

\section{Acknowledgment}

This work is supported by National Science Foundation of China Grant No. 61070021.

\section{References}

[1] A. P Li, Cai L, L. Y Xu, Virtual enterprise based interactive modeling and implementation for collaborative product ion information, Chinese Journal of Construction Machinery, vol. 7, 2009, pp. 233-238. (in Chinese)

[2] N. Erasala, C. David, Enterprise Application Integration in the electronic business world, Computer Standards Interfaces, vol. 25, 2003, pp. 69-82.

[3] Y. G Li, Z. S Ji, Y Lin, Application Integration of Shipbuilding Virtual Enterprise with SOA and Web Service, Computer Engineering, vol. 34, 2008, pp. 263-265. (in Chinese) 
[4] R. K. L. Ko, S. S. G. Lee, W. E. Lee, Business process management(BPM) standards: a survey, Business Process Management Journal, vol. 15, 2009, pp. 744-788.

[5] M. Weske, W. Aalst, H. Verbeek, Advances in business process management, Data and Knowledge Engineering, vol. 50, 2004, pp. 1-8.

[6] M. Wooldridge, N. R. Jennings, D. Kinny, The GAIA methodology for agent-oriented analysis and design, Autonomous Agents Multi-Agnets Systems, vol. 3, 2000, pp. 285-312.

[7] L Shang, J Yao, Research on process modeling for virtual enterprise based on Petri net, Machinery Design and Manufacture, vol. 3, 2007, pp. 174-176. (in Chinese)

[8] H Huang, Design of virtual Enterprise Workflow Process based on Petri net, Wuhan: Wuhan University of Technology, Communications and Information Systems, 2008. (in Chinese)

[9] K. Jensen, Colored Petri nets: basic concepts analysis methods and practice use, New York: Springer-Verlag, vol. 2, 1995.

[10]J. Z Wang, Y. L Zhang, J. Y Luo, Performance analysis of new stochastic colored Petri nets, Computer Applications, vol. 28, 2008, pp. 292-293. (in Chinese)

[11]X. S Guo, L. Y Sun, S Xu, Study on a Kind of Reliability Model on Multi echelon Supply Chain Based on SCPN, Operations Research and Management Science, vol. 15, 2006, pp. 292-293. (in Chinese) 